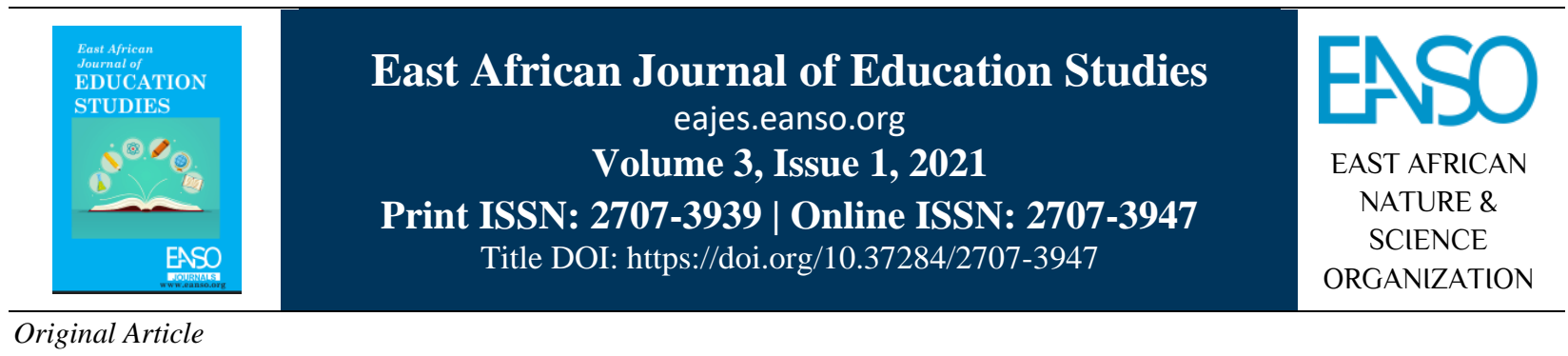

\title{
Analysis of Stakeholders Involvement in the Implementation of the M.A. Literature Curriculum at Kabale University Using E-Learning Approach
}

\author{
Ocan Johnson $^{* 1}$ Tukwasibwe Constance ${ }^{1}$ \& Oketch Chrysostom ${ }^{1}$ \\ $1^{*}$ Kabale University, P. O. Box 317, Kabale, Uganda. \\ *ORCID: https://orcid.org/0000-0003-2577-6780; Correspondence Email: jocan@kab.ac.ug.
}

Article DOI: https://doi.org/10.37284/eajes.3.1.384

\section{Date Published: ABSTRACT}

13 August 2021 The purpose of the study was to report on an empirical study of the involvement of stakeholders in the implementation of the MA Literature Curriculum at Kabale

Keywords: University using e-Learning approach. The study used a mixed method approach of both qualitative and quantitative techniques. In this study, curriculum stakeholders

E-Learning, were found to significantly influence curriculum development, hence collaboration Implementation, with these stakeholders through feedback, critique and advice can only serve to meld

Stakeholder's,

Literature,

Curriculum the content and method of delivery of the curriculum. This study extends the application of a modified curriculum development process model based on ADDIE (analysis, design, development implementation and evaluation). It recognizes the different stakeholders and their input for curriculum innovation. Therefore, identifying, understanding and managing stakeholders' involvement in curriculum implementation is a key driver in the curriculum development. This paper is not concerned with comparing and exploring possible techniques of identifying university stakeholders with the aim of choosing the most suitable one, but it is intended to clarify on the categorization of the internal and external stakeholders.

\section{APA CITATION}

Johnson, O., Constance, T. \& Chrysostom, O. (2021). Analysis of Stakeholders Involvement in the Implementation of the M.A. Literature Curriculum at Kabale University Using E-Learning Approach. East African Journal of Education Studies, 3(1), 199210. https://doi.org/10.37284/eajes.3.1.384.

\section{CHICAGO CITATION}

Johnson, Ocan, Tukwasibwe Constance and Oketch Chrysostom. 2021. "Analysis of Stakeholders Involvement in the Implementation of the M.A. Literature Curriculum at Kabale University Using E-Learning Approach". East African Journal of Education Studies 3 (1), 199-210. https://doi.org/10.37284/eajes.3.1. 384.

\section{HARVARD CITATION}

Johnson, O., Constance, T. and Chrysostom, O. (2021) "Analysis of Stakeholders Involvement in the Implementation of the M.A. Literature Curriculum at Kabale University Using E-Learning Approach", East African Journal of Education Studies, 3(1), pp. 199-210. doi: 10.37284/eajes.3.1. 384.

$199 \mid$ This work is licensed under a Creative Commons Attribution 4.0 International License. 


\section{IEEE CITATION}

O. Johnson, T. Constance, and O. Chrysostom, “Analysis of Stakeholders Involvement in the Implementation of the M.A. Literature Curriculum at Kabale University Using E-Learning Approach”, EAJES, vol. 3, no. 1, pp. 199-210, Aug. 2021.

\section{MLA CITATION}

Johnson, Ocan, Tukwasibwe Constance and Oketch Chrysostom. "Analysis of Stakeholders Involvement in the Implementation of the M.A. Literature Curriculum at Kabale University Using E-Learning Approach". East African Journal of Education Studies, Vol. 3, no. 1, Aug. 2021, pp. 199-210, doi:10.37284/eajes.3.1.384.

\section{INTRODUCTION}

The term "stakeholder involvement" has numerous definitions, many of which are linked to the context in which the term is being used. Two general definitions are useful in the context of this paper the first of these is that "a stakeholder" is a person or group with an interest, involvement or investment in something (Stufflebeam et al., 1985). In the second definition, the term is used to describe people who will be affected by a project, or who can influence it, however they are not directly involved in doing the work (Richards, 2001; Paltridge \& Starfield, 2013). Universities have a variety of stakeholders from whom they collect invaluable feedback regarding their needs and requirements related to education processes. These stakeholders can be divided into two distinct groups; curriculum stakeholders and professional stakeholders.

Curriculum stakeholders are key drivers of the content, method of delivery, evaluation requirements and scope of the curriculum that qualifies for a certain profession. Professional stakeholders have a broader interest in specific professions, professional attributes of graduates, their work capabilities and conditions especially career development and knowledge and competencies. In addition, stakeholder's involvement is important for curriculum developers to be able to know and describe the competency gap that is already possessed or mastered by the learners in terms of what is needed during the times they follow the program or later. This point of view was supported by Ornstein and Hunking (1998); they claimed that stakeholders occupy a central position in curriculum decision making. They also added that stakeholders are the only ones who can decide on the aspects of the curriculum that is newly developed, as a result when developing a curriculum, not only learners' needs but also stakeholders need should be taken into consideration.
The reason underlying this vast study of stakeholder's involvement is the convincing fact that stakeholder involvement is the foundation or basis for decision-making related to the curriculum development (Soruc, 2012). Through this stakeholder involvement stage, curriculum policymakers will acquire the learners' data, objectives, learning projections, learning style and learning strategy preferences, as well as the literary situation that they will enter into so that the curriculum developers can develop the curriculum components effectively and systematically (Paci, 2013).

The fundamental question to ask when considering the issue is "why should any potential stakeholder wish to become involved in the promotion of a course programme?' Several answers are possible, and in reality, stakeholder involvement may well be based on a mixture of some or all of them. They include altruism - we do it because we believe it is the right thing to do irrespective of cost. We do it as an investment - this is because we perceive that there will be a return on our investment. We do it by compulsion - because we have been told we have to. The significant risk with this approach is that we will do the absolute minimum. Lastly, we do it because of the lost opportunity - we do it because the potential benefits are so great that we cannot afford not to, or that our competitors are doing it, thus we must do the same to maintain our market position.

E-learning is an innovative approach to delivering a well-designed, learner-centred, interactive learning process facilitated by an open, flexible, and distributed learning environment by utilizing a variety of digital technology or information and technology as well as communication tools (Fee, 2009). As an innovative approach, e-Learning demands a paradigm shift not only from the learners, but also from the Lecturers, instructors, trainers, administrators, technicians, and other support staff. In e-learning implementation and in 
an effort to create an open, flexible, and distributed learning environment, the learning program or curriculum developers should explore important issues related to the various dimensions of elearning environments. To achieve this goal, a comprehensive stakeholder involvement is required (Azimi \& Rahmani, 2013).

To create an e-learning environment with the elearning system, there are eight dimensions that have to be observed in order to realize an effective process. These eight dimensions of e-learning include (1) institutional, (2) pedagogical, (3) technology, (4) interface design, (5) evaluation, (6) management, (7) source support, and (8) ethics (Khan, 2005a). These eight dimensions have their respective subdimensions. Each of these subdimension has specific aspects of the e-learning environment. First, the institutional dimension is a dimension that deals specifically with matters related to administration, academics, and service affairs to the learners that are associated with elearning. Second, the pedagogical dimension in this e-learning refers to the learning and teaching process that focuses directly on the content analysis, audience, objectives, media, approaches, design, and learning strategies. Third, the technology dimension is related to technology and infrastructure issues including infrastructure planning as well as hardware and software provision. Fourth, the interface design dimension refers to all aspects that are seen and perceived by the learners' sense of presence in the eLearning program. Fifth, the evaluation dimension for elearning includes assessment for the learners and evaluation for the instructional programs and learning environments. Sixth, the management dimension refers to the management of the learning environment and information distribution. Seventh, the source support dimension is related to providing the online support and resources necessary for a meaningful learning to be realized. Eighth, the ethics dimension focuses on e-learning that is associated with social and political influences, cultural diversity, bias, geographical diversity, learners' diversity, technological ethics, and things that are related to legal issues.

These eight dimensions and the sub dimensions make their respective contributions to the implementation of a curriculum using e-learning from the stages of planning, design, production, evaluation, delivery and maintenance, instruction, and marketing (Barrett \& Moore, 2010). These eight dimensions are crucial in the discharge of the MA Literature curriculum at Kabale University in Uganda.

Stakeholder involvement process is a kind of "bridge" to address the gaps existing in literature training curriculum with the learners' needs. To that end, the curriculum developers must perform a thorough, carefully consider a stakeholder involvement. They should also periodically evaluate, determine, or decide whether the running program is still accommodating the learners' needs or has deviated from the expectations of the learners (Altschuld et al., 2010). This is in line with what was proposed by Cannaday (2009) that in literature teaching, stakeholder involvement is the stage of determining the learners' needs in the program as well as simultaneously structuring those various needs according to the priority of the learners. From this stage, it can be seen that the process of selecting and evaluating a variety of information has been conducted since the beginning of the curriculum development. The subjective and objective information is gained through questionnaires, tests, interviews, and observations (Chegeni \& Chegeni, 2013; Kaewpet, 2009).

In the context of Kabale University Master of Arts in Literature Learning, stakeholder involvement is an important investigative stage that was conducted mandatorily as a minimum requirement by the National council for Higher Education (NCHE, 2014) to identify the needs and actual gaps of the learners. From this investigation, curriculum developers a variety of information is obtained regarding the purpose, content, literary background, learning style preferences, teaching strategies, the motivation of the learners, outcomes, and also the commitment of learners when enrolling in a program. This article presents the results of a case study on the importance of stakeholder involvement in the implementation of the MA Literature program at Kabale University.

The paper consists of six sections. The introduction which briefly describes the narrative of stakeholders' involvement in the implementation of the MA Literature curriculum at Kabale University 
using e-learning approach, the second part addresses the problem statement. The third part introduces the conceptual framework which briefly highlight the ADDIE model which is designed to analyse the phases of curriculum development. The fourth part discusses the methods of data collection, the fifth discusses the results and finally the conclusion.

\section{Problem Statement}

The research problem addressed in this paper is how to identify and select key curriculum stakeholders whose involvement can be of great importance for the curriculum development process, as well as how to collect and process their requirements. The primary research goal is to devise an analysis subprocess of the curriculum development which would facilitate selection of stakeholders based on a detailed description of their roles in the process of curriculum implementation. Additionally, the paper presents a modified scenario for gathering, processing and using data on stakeholder's involvement in the analysis phase of the curriculum development, aimed at key competences of a study programme.

\section{CONCEPTUAL FRAMEWORK}

University curriculum development is a complex sub-process. Its complexities are predetermined by its influences on development- many stakeholders, each taking its own stance: researchers, lecturers, students, industry, social organizations, parents and politics (SLO, 2009). Taking into account the definition of stakeholder involvement which is linked to the context in which the term is being used. The word is used to describe people who will be affected by a project, or who can influence it, but who are not directly or indirectly involved in doing the work (Richards, 2001; Paltridge \& Starfield, 2013). It becomes clear that stakeholder involvement in the curriculum implementation must be acknowledged and reconciled with different interests.

Stakeholder involvement in the implementation of a curriculum sub-process requires a continuous review and adjustment of its numerous features with regional and national interests, universities strategic documents requirements set by national and international accreditation standards, as well as individual interests of teaching, research, staff and students.

Curriculum development model presented in this paper was developed based on ADDIE model. This is a general-purpose development model, mostly used by instructional designers, developers and trainers for creating instructional products. ADDIE model is a generic, systematic, step by step framework for iterative design, structured into five phases: Analysis, Design, Development, Implementation and Evaluation. 
Figure 1: Curriculum Development Model

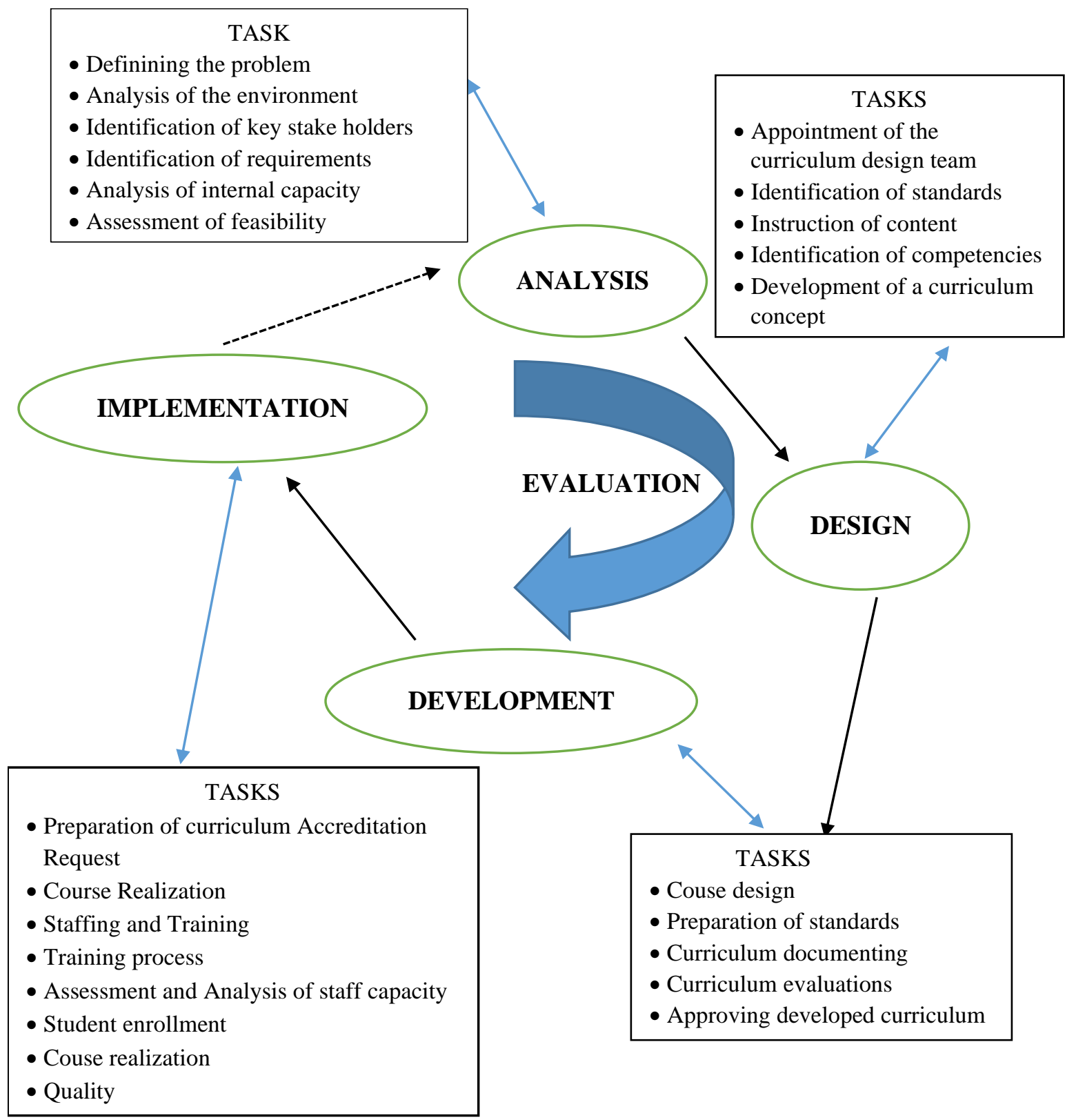

Source: Matkovic et al. (2014)

The following model has been developed to provide a framework of stakeholder engagement to be used by those responsible for implementing programmes of study at university levels. The model describes the phases during which different stakeholders are primarily involved. The model illustrates how the dynamic involvement of stakeholders can change through the phases of engagement. The phases presented in the model are qualitatively different from each other, pose different challenges for successful implementation and have different key stakeholders.

In the drawing in Figure 1 generally, the closer the stakeholder is to the centre of the circle the greater their overall involvement in curriculum development process. Therefore, we can see that typically curriculum design team have a greater role in an intervention than do agencies such as students or Parents. In other words, stakeholders as

203 This work is licensed under a Creative Commons Attribution 4.0 International License. 
implementers often have a greater role in the realization of an intervention than do those in the analysis phase. There are exceptions to this principle, for example, government initiatives to assess and analyse the staff capacity through a workplace programme. Clearly, in such circumstances the role of the government is absolutely key. It is important to note that all stakeholders have the ability to interact with one another in order to facilitate the implementation of a curriculum. However, some stakeholders are more likely to interact than others. It is clear that parents and students are more likely to be in dialogue than a teaching staff.

The analysis phase is the most important phase in the ADDIE model. Analysis is the process of defining audience, goals and objectives based on the identified problem and analysis of the environment and stakeholder's requirements. This permit assessment of the development in terms of technological and systems feasibility, legal feasibility, operational feasibility, technical feasibility and economic feasibility. During this phase, we define and develop a clear understanding of the audience's needs and constraints, existing knowledge, skills and the desired outcome of the course.

The design phase of the proposed model is aimed at developing a clear concept of the future curriculum, which encompasses definition of course objectives, lesson planning, topic content, training methodology, presentation methods, learner exercises and assessment criteria systematically structured in a course map. The most critical activity represents a basis on which the future curriculum will be built.

The development phase involves detailed development of courses identified in the course map (course name, code contact hours, credit unit, brief description, course objectives, learning outcomes and detailed indicative content) and preparation of learning materials and supporting technology (textbooks, visual aids, knowledge assessment tools, etc.). This phase involves thorough documentation of a future curriculum.

The implementation phase is where developed course is actually put into action and the final product developed based on needs and errors. Implementation is a recurring process which involves effective and efficient execution of defined courses, initial implementation of a curriculum involves significant effort on training staff for teaching newly developed courses.

The evaluation phase in the proposed model considers feedback from key stakeholders and continuous quality assessment. The feedback gathered during this phase provides significant insight into reactions of clients, suppliers and intermediaries to the actual realization of a study programme, and the effects of its realization. Data gathered trough surveys can be used for fine-tuning of the programme and set competencies.

At Kabale University various stakeholders participate in the realization of the five stages of the ADDIE model. Therefore identifying, understanding, and managing stakeholders are key organizational activities (Simms \& Chapleo, 2010). This paper is not concerned with exploring and comparing possible techniques and strategies for identifying university stakeholders with the aim of choosing the most suitable one, but rather employs review and analysis of prominent literature. A substantial number of research studies that differently categorize external stakeholders was analysed. The most common classification, which involves dividing them into internal and external stakeholders is presented in Table 1

Table 1: University stakeholders in Curriculum Development process

\begin{tabular}{l|l}
\hline External Stakeholders & Internal stakeholders \\
\hline - Employers & $\bullet$ Governing board \\
- Government and other NGO's & $\bullet \quad$ Management (HoD, Deans and DVC) \\
- Parents & $\begin{array}{l}\text { Employees (teaching and research staff, } \\
\text { - Former and potential students }\end{array}$ \\
\hline
\end{tabular}

204 | This work is licensed under a Creative Commons Attribution 4.0 International License. 


\begin{tabular}{ll|l}
\hline External Stakeholders & Internal stakeholders \\
\hline - & Suppliers (alumni, high school, service & \\
providers, other universities) & \\
- Competitors (direct, potential, substitutes) & \\
- $\quad$ Donors & \\
- Intermediaries (banks, funds, science and & \\
technology) & \\
- Communities & \\
\hline
\end{tabular}

Source: (Mainardes, Alves \& Raposo, 2010).

Among all identified external and internal stakeholders, only a portion of them have considerable interest in how curriculum is designed and delivered, as well as what skills, knowledge and competencies it provides to graduates. University stakeholders with impact on the curriculum development process is divided into curriculum and professional stakeholders. Curriculum stakeholders are key informers and drivers of the content, method of delivery, evaluation requirements and scope of curriculum that qualifies for certain profession. Professional stakeholders have a broader interest in specific professions, professional attributes of graduates, their work capabilities and conditions, specifically career development and knowledge and competencies (Mainardes et al., (2010).

Curriculum stakeholders are essential to curriculum development. Collaboration with these stakeholders and an open dialogue that invites recommendations, feedback, critique and advice can only serve to meld the content and method of delivery of the curriculum to meet the needs of the communities that graduates will be employed to serve.

\section{METHODS}

In the beginning of the quantitative analysis process of this study, the researchers embarked on pre-data analysis activities: screening, coding, data entry and cleaning. The researchers adopted descriptive statistics to describe the basic features of the data in the study, as they provide simple summaries of the sample and the measures. This was followed by other important analyses including response rate and non-response bias, data normality test, reliability test and validity test. In this study, a total of 180 survey questionnaires were sent out and 120 completed ones were received. Thus, the study recorded a response rate of $68.9 \%$. Although it became evident that there is a high non-response rate among the $\mathrm{P}+\mathrm{M}-$ group, cumulatively the high response rate of the survey helped lower the risk of non-response bias on the study findings (Massey and Tourangeau, 2013).

Bivariate test and multinomial logistic (MNL) analyses were both adopted in this study. These techniques helped to provide a powerful means for analysing unordered categorical data, and allow numeric and categorical explanatory variables to be entered into the models with parameters and modelfit statistics interpreted in much the same way as for a standard logistic regression model (Hutcheson and Moutinho, 2008). Given that the key stakeholders (Deans, Directors, members of management, accountants, student leaders and other cost centre managers to assess their perspectives on systematic engagement and policy-formulation of the university curriculum cannot be determined by a single linear prediction, adoption of both the bivariate and MNL models is considered appropriate for this study. That is, whereas the bivariate test can reveal association among variables, the MNL provides the extent of a significant causal relationship. Thus, the use of both analysis techniques helped the researcher to holistically explain the relationship between the dependent variable and the continuous-level (interval or ratio scale) independent variables. In this study, for example, the researchers considered age, gender and educational needs of the respondents as the numeric and categorical explanatory variables for carrying out the analysis.

Analysis of Internal stakeholders' capacity - This paper provides a short conceptualisation of stakeholder engagement, followed by 'design principles' that we put forward based on a combination of existing literature and new empirical insights from our recently completed longitudinal study of stakeholder engagement. The design 
principles for stakeholder engagement are organised into three groups, namely organisational, values and practices. The organisational principles are to clarify the objectives of stakeholder engagement; embed stakeholder engagement in a framework or model of research use; identify the necessary resources for stakeholder engagement; put in place plans for organisational learning and rewarding of effective stakeholder engagement; and to recognise that some stakeholders have the potential to play a key role. The principles relating to values are to foster shared commitment to the values and objectives of stakeholder engagement in the project team; share understanding that stakeholder engagement is often about more than individuals; encourage individual stakeholders and their organisations to value engagement; recognise potential tension between productivity and inclusion; and to generate a shared commitment to sustained and continuous stakeholder engagement. Finally, in terms of practices, the principles suggest that it is important to plan stakeholder engagement activity as part of the research programme of work; build flexibility within the research process to accommodate engagement and the outcomes of engagement; consider how input from stakeholders can be gathered systematically to meet objectives; consider how input from stakeholders can be collated, analysed and used; and to recognise that identification and involvement of stakeholders is an iterative and ongoing process.

Most of the stakeholder engagement literature highlights the broad range of activities in which stakeholders can engage depending on their own skills and attributes and the capacity and wishes of the researchers conducting specific studies. At the broadest level of a research system, or research funding body, Lomas (2000) claimed there were many activities in which stakeholders could be engaged in a 'linkage and exchange' approach for curriculum development research in education. These were setting priorities, funding programmes, assessing applications, conducting research and communicating findings. The importance of engaging a wide range of stakeholders in prioritysetting has often been emphasised. The pioneering study by Kogan and Henkel (2006) analysed both the importance of engaging policy-makers in setting research agendas to meet their needs, and the obstacles to making the process work well. These obstacles included issues around how far the assessment of needs-based research should focus on the relevance and practical impact of the research as well as its scientific merit. Many of the more recent studies explicitly examining stakeholder engagement also set out a range of activities in which stakeholders may be involved. These are often related to phases of the research processes. Concannon et al. (2012) provide a list of roles related to stages and used the identified roles in a subsequent review Concannon, (2014).

Assessment of Feasibility - This activity involves performing several analyses aimed at concluding whether the introduction of a new curriculum would be successful or not. Introduction of a new curriculum is examined from financial and market perspective. The key questions that need to be answered within this activity are whether it would be financially reasonable to implement it. A significant factor in the analysis of feasibility in is related to capacity of human resources identified in the previous stage. For a successful implementation, present teaching staff has to possess sufficient expertise to execute courses that would provide compliance of future students' competences with stakeholders' involvement clearly identified. In the event of a negative assessment of feasibility, a university may explore an option to develop a joint study program to ensure financial viability of a new curriculum.

\section{RESULTS}

\section{Empirical Results}

\section{Characteristics of the Sampled Population}

According to the study data set, the average age of respondents for the study was 32 years. In terms of gender, the sampled population constituted 131 (67.9\%) females and $62(32.1 \%)$ males. Adding to this, in terms of the marital status of the respondents, $155(80.3 \%)$ were married, 14 (7.3\%) single, 2 (1\%) widowed, 5 (2.6\%) divorced and 17 (8.8\%) separated. From the study data, Education emerged as the highest occupation type among study respondents, recording $48.2 \%$ of the total. While journalism was observed as the second highest occupation type with a record of $26.4 \%$, $25.4 \%$ of the respondents indicated their 
involvement in other occupation types such as the service sector and trading. Again, the data obtained further indicated that there is varying educational status among study respondents. It is clear that Bachelor's Degree holders constituted the highest proportion when considering the educational status of the study's respondents, recording $35.2 \%$. While $33.7 \%$ of respondents chose high school education to describe their status, those in the tertiary group constituted the lowest, where $31.1 \%$ of respondents were recorded.

The stakeholder involvement process in the MA Literature curriculum implementation was carried out in Kabale University in Uganda by referring to the principle that e-learning is a form of learning that can as best as possible "transfer" the real class into the virtual classroom with adequate technology packaging. Based on this principle, the institution conducted the stakeholder involvement to develop a program plan by filtering information from the learners in the form of personal data, proficiency level, and early language competence, with an emphasis on literary skills to be improved, and specific preferences related to the background of the learners. These aspects were listed on the registration form that the learners had to fill in before enrolling themselves in the program. Based on the interview, the needs assessment was mainly conducted by the teachers and the R\&D division. Stakeholder involvement conducted by the teachers was in the form of verbal questions and answers related to the initial literary competence, the level to be entered, and the topics that interested the learners.

Researchers also explored information related to the technical proficiency of the learners as an initial prerequisite for enrolling on the MA Literature program using the e-learning approach, including the capacity to use the Internet to ensure that the elearning process can run smoothly. The stakeholder involvement conducted by the R\&D division was focused on the options for the learning materials and the media that are going to be used in the program that the learners will take. Information extracted from the needs assessment process was the source for developing the MA Literature curriculum of Kabale University.
In relation to the curriculum, with no comprehensive stakeholder involvement, it was found out that the program was still experiencing problems in the development of the e-learning approach due to the ungrouped competence and the inaccurate level of placement. With such conditions, the implementation of the MA Literature curriculum of Kabale University using the e-learning approach was equated with the curriculum of the onsite learning dimension. The step taken by the institution is more related to the renewal of only one of the components of the curriculum, which is the learning materials. Every learner who is enrolled on the MA Literature program was offered a new learning experience by adjusting them to the interest of the learner. Other curriculum components are not comprehensively updated. This will certainly have an impact on the achievement of the course learning objectives.

Data analysis obtained from the interviews and document study on the stakeholder involvement in the implementation of the MA Literature curriculum at Kabale University using e-learning approach conducted at the institution where this study took place has not adequately covered the overall dimensions of the Implementation of the MA Literature curriculum at Kabale University using elearning approach, as described by Khan, i.e. (1) institutional, (2) pedagogical, (3) technology, (4) interface design, (5) evaluation, (6) management, (7) source support, and (8) ethics, were covered Khan (2005). Those dimensions are pedagogical, technology, and interface design. In addition, not all sub aspects in the three dimensions are covered in the stakeholder involvement process. As a result, the profile of the learner is incomplete and this has an impact on the preparation of the curriculum, which is less comprehensive. This impact will certainly lead to a chain effect on the learning process that appears on the number of improvisations in the learning process and the shifting focus of learning or the literary skills that are going to be mastered. This impact will certainly lead to a chain effect on the subsequent learning process that appears on the number of improvisations in the learning process and the shifting focus of learning of the literary dimension that is going to be mastered. 
The limitations of information obtained from a less comprehensive stakeholder involvement make the learning process not optimal in relation to the "sense of presence," which becomes the core of learning with an e-learning system. The interface design models that is designed to explore a range of literary activities that is appropriate with the learning styles and learning strategies on the MA Literature was also not diverse. This can certainly be overcome by providing various programs or applications that can be implemented in the MA Literature curriculum application using the e-learning approach so that in addition to face-to-face encounters with the learners, there are other applications that can be accessed by the learners independently to improve their literary competence.

\section{CONCLUSION}

Given the crucial roles that stakeholders play in the internal and external environments in which the organization competes, the methodological approach and findings offer significant insights for strategic managers. Study findings can serve as a baseline idea for strategic managers and planners in developing decision-making models and frameworks that are sensitive to current stakeholder orientation challenges, a challenge that many firms continue to grapple with in the context of complex environments. Adding to this, based on consideration of the limited resources available to strategic managers, the methodological approach of the study is of significant value. That is, despite the bivariate findings showing that considered variables seemed to have similar significance in understanding stakeholder responses, the further ADDE model helped to unveil the extent to which education predicts their attitudes towards social practices. Thus, the level of uncertainties and risks associated with resource allocation towards creating new ways of strategic planning that result in buy-in from stakeholders is minimized, if not eliminated.

From a policy perspective, it is possible that the study findings are able to shape education policy. It has become increasingly evident that policymakers' ability to diagnose connections between various aspects of contemporary society has outgrown their ability to find appropriate solutions for emerging problems. Thus, agreeing that each single participant in a decisional process has different characteristics and can still behave unpredictably by breaking the rules that should theoretically be respected, focusing on strategies that are sensitive to the nature of the interest of actors is imperative. The application of the findings of the study in education policy planning and implementation can be an appropriate remedy, as it can guide policymakers to define the style, rationality and logic of background salient characteristics that influence the actions of a given stakeholder. Significantly, this can help enhance chances of mediation among actors, and minimize conflicts within the decisional process when handling collective problems.

In conclusion, understanding a stakeholder's willingness to embrace social intervention initiatives within host communities can offer valuable and transferable lessons to resource and education policymakers, in both the corporate and the government sector.

Overwhelmingly it was discovered that stakeholder Involvement is an important process in the implementation of the MA Literature curriculum at Kabale University using the e-learning procedure because it will help the learners and training providers in designing the planning, implementation, and assessment of the learning program. Stakeholder involvement in the organization of e-learning will produce accurate, meaningful, and useful information when it includes the institutional, pedagogical, technology, interface design, evaluation, management, source support, and ethics dimensions. With these eight dimensions included in the stakeholder involvement process, the curriculum or the MA Literature e-learning program developers can provide assurance that the learning process that will be followed by the learners can take place according to the objectives and with an effective process as well as with outcomes that are appropriate to the initial planning.

\section{ACKNOWLEDGEMENT}

This article was supported by Kabale University Research Grant from the Directorate of Research and Publication 2021-37456-177-01. The authors are grateful to the sponsors. Also, many thanks to all study participants, who generously donated their time and provided invaluable information for the study. 


\section{REFERENCES}

Altschuld, J. W. \& David, D. (2010). Needs Assessment: An Overview. London. Sage

Azimi, H. M., \& Rahmani, R. (2013). Importance of Needs Assessment for Implementation of Elearning in Colleges of Education. International Journal of Information and Computation Technology, 3(5), 377-382.

Barrett, T., \& Moore, S. (2010). New approaches to problem-based learning: Revitalising your practice in higher education. Routledge.

Bryman, A (2001). Social Research Method. Oxford University Press

Bryman, A. \& Bell, E. (2015). Business Research Methods. New York, NY: Oxford University Press.

Cannaday, J. (Ed.). (2018). Curriculum Development for Gifted Education Programs. IGI Global.

Chapleo, C., \& Simms, C. (2010). Stakeholder analysis in higher education: A case study of the University of Portsmouth. Perspectives, 14(1), 12-20.

Chegeni, N., \& Chegeni, N. (2013). Language curriculum development and importance of needs analysis. Department of English, Islamic Azad University, Iran. ELT Voices-India, 3(4), $1-13$.

Concannon, T. W., Fuster, M., Saunders, T., Patel, K., Wong, J. B., Leslie, L. K., \& Lau, J. (2014). A systematic review of stakeholder engagement in comparative effectiveness and patientcentered outcomes research. Journal of general internal medicine, 29(12), 1692-1701.

Fee, K. (2013). Delivering E-learning. A Complete Strategy for Design, Application and Assessment. Development and Learning in Organizations, 27(1).

Hutcheson GD, Moutinho LA. 2008. Statistical Modelling for Management. Sage Publications: Thousand Oaks, CA.
Kaewpet, D. (2009). Encyclopaedia of Language Teaching and Learning. Routledge. Abingdon.

Khan, B. (2005a). E-learning Quick Checklist. Hershey: Information Science Publishing. India.

Khan, B. (2005b). A comprehensive e-learning model. Journal of e-learning and Knowledge Society, 1(1), 33-44.

Kogan, M. \& Henkel, M. (1983). Government and Research: The Rothschild Experiment in a Government Department. London: Heinemann Educational Books

Lomas, J. (2000). Essay: Using 'Linkage and Exchange'To Move Research Into Policy At A Canadian Foundation: Encouraging partnerships between researchers and policymakers is the goal of a promising new Canadian initiative. Health affairs, 19(3), 236-240.

Mainardes, E. W., Alves, H., \& Raposo, M. (2010). An exploratory research on the stakeholders of a university. Journal of Management and strategy, 1(1), 76.

Massey DS, Tourangeau R. 2013. Where do we go from here? Nonresponse and social measurement. The ANNALS of the American Academy of Political and Social Science 645: 222- 236.

Matkovic, P., Tumbas, P., Sakal, M., \& Pavlicevic, V. (2014). Curriculum Development Process Redesign Based on University-Industry Cooperation. In Proceedings of the 6th International Conference on Education and New Learning Technologies (EDULEARN) (pp. 4113-4123).

Mugenda, O. M. \& Mugenda, A. G. (1999). Research Methods- Quantitative and Qualitative Approaches. Nairobi, Kenya: ACTS press.

National council for Higher Education (NCHE). (2014). Quality Assurance Framework for Universities and the Licensing process of Higher Educational Institutions in Uganda. Kyambogo, UG: National council for Higher Education. 
Ornstein, A. C. \& Hunkins, F. P. (1998). Curriculum Foundations, Principals and Issues. Allyn \& Bacon, US.

Paci, M. (2013). Needs analysis and environment analysis: Designing an ESP curriculum for the students of the Polytechnic University of Tirana. Journal of Educational and Social Research, 3(7), 425-430.

Paltridge, B. \& Starfield, S. (eds) (2013). The Handbook of English for Specific Purposes. London: Wiley

Richards, J. C. (2001). Curriculum Development in Language Teaching. Cambridge University Press.

SLO Netherlands Institute for Curriculum Development. (2009). Curriculum in Development. Enschede, Netherlands.

Soruc, A. (2012). The role of needs analysis in language program renewal process. Mevlana International Journal of Education, 2(1), 36-47.

Stufflebeam, D. L., McCormick, C. H., Brinkerhoff, R. O., \& Nelson, C. O. (2012). Conducting educational needs assessments. Hingham, MA: Kluwer-Nijhoff Publishing. 